\title{
Review and Thermodynamic Calculation of Gas-based Shaft Furnace Direct Reduction Ironmaking
}

\author{
Weiming Luo $^{1}$ \\ ${ }^{1}$ Energy and Power Engineering, Xi'an Jiaotong University, 710049, China
}

\begin{abstract}
Different techniques have been used to study the reduction process of iron ore. In this paper, the reduction process of iron ore by $\mathrm{CO}$ at $200 \sim 1200^{\circ} \mathrm{C}$ is calculated. The effects of reducing agent overdose, reducing temperature and $\mathrm{V}_{\mathrm{CO} 2} /\left(\mathrm{V}_{\mathrm{CO}}+\mathrm{V}_{\mathrm{CO} 2}\right)$ on reducing degree were studied. The results show that the reduction degree increases with the increase of reducing agent and slows down gradually. During the reduction process, the reduction degree decreased significantly with the increase of $\mathrm{V}_{\mathrm{CO} 2} /\left(\mathrm{V}_{\mathrm{CO}}+\mathrm{V}_{\mathrm{CO} 2}\right)$. In this temperature segment, the reduction degree has a peak.
\end{abstract}

\section{Introduction and literature review}

Vanadium-titanium magnetite (VTM for short in this paper) is one of the main raw materials for extracting iron, titanium, vanadium and other important metal elements. It is most common in Australia, China, Russia and South Africa. China's proven reserves of VTM amount to 30 billion tons (about 20 billion tons in Panzhihua city, Sichuan province, and 8.5 billion tons in Chengde city, Hebei province). Up to now, no country has realized the efficient simultaneous extraction of $\mathrm{V}, \mathrm{Fe}$ and $\mathrm{Ti}$, which means that resources are unceasingly wasted. Therefore, only by doing sufficient thermodynamic calculation and kinetic research and developing the efficient extraction technology of VTM, can the element be fully utilized. In conclusion, this paper has profound significance.

The difficulty of reducing Vanadium titanium magnetite is from the combination of oxide and titanium and the complexity of the reaction process of ore. In particular, ulvite with the same inverse spinel as magnetite will form a complete solid solution with magnetite at a certain temperature, making extra complexity of the reaction. The main process flow is generally shown in FIG 1.

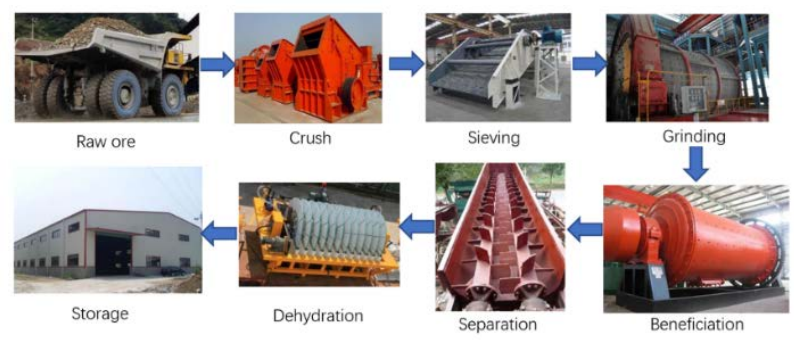

FIG.1 process flow (three-stage open-circuit crushing process adopted; Grinding includes coarse).
Blast furnace ironmaking-converter extraction of vanadium is the mainstream technology for smelting VTM at home and abroad [1-4]. The former Soviet Union has conducted four industrial tests of high-titanium blast furnace slag on small blast furnaces below $270 \mathrm{~m}^{3}$. The final slag $\mathrm{TiO}_{2}$ was as high as $38-40 \%$, and qualified pig iron was obtained. However, the operation of the blast furnace is extremely unstable. Suspended material, collapsing material, slag iron thickening and hearth accumulation often occur, and the coke ratio is high. Finally, only the blast furnace smelting technology with a final slag $\mathrm{TiO}_{2}$ content below $15 \%$ is mastered. Researches on the blast furnace method in countries such as Northern Europe and North America also started earlier, but they have never been resolved. The problem that the slag becomes sticky after the Ti content in the slag is greater than $10 \%$.

Since the 1960s, China has conducted research and development on the utilization technology of VTM in the Panxi region. With the advantages of concentrating domestic technical force, manpower and material resources in China 's system, it took only five years to overcome the technical difficulties that have block the world for more than 100 years. The blast furnace smelting VTM technology was developed. The general process is shown in FIG 2. 


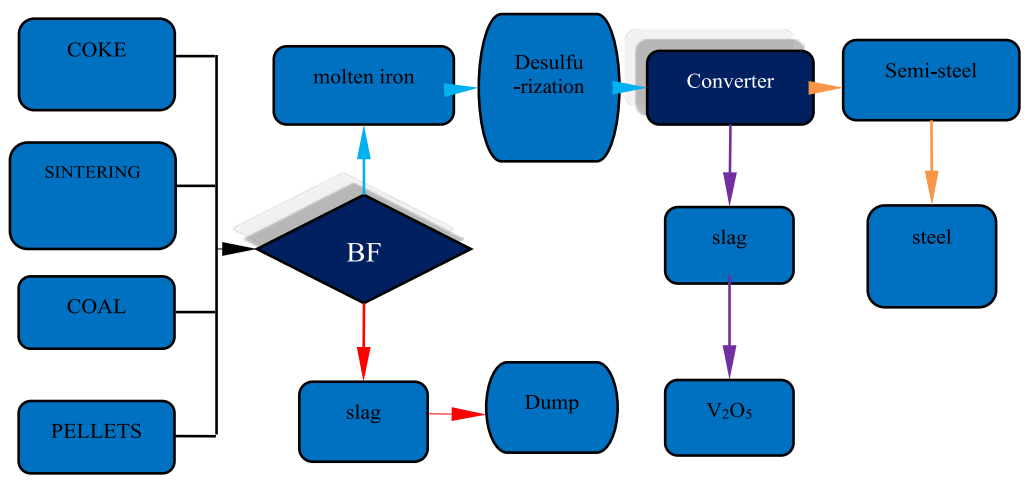

FIG 2 Blast furnace smelting process of VTM.

And a large steel production base was built in Panzhihua. The content of $\mathrm{TiO}_{2}$ can be stably produced for a long time under the condition of $25 \%$, which has played an irreplaceable role in China's economic development, especially in the southwestern region. In recent years, Pangang has adopted innovative technologies in the separation and smelting of VTM, so that the furnace utilization factor has been greatly improved. This technology divides the $\mathrm{TiO}_{2}$ in the original ore into two parts, of which $54 \%$ of $\mathrm{TiO}_{2}$ enters the iron ore concentrate through beneficiation, and finally enters the pig iron (about $\mathrm{Ti}$ 19.19\%) and slag (containing $\mathrm{TiO}_{2} 22-$ $24 \%$ ), and the rest enters Dressing tailings. The same is true for vanadium. About $46 \%$ of the V2O5 is introduced into the molten iron with the iron ore concentrate, and then vanadium is extracted. The unrecyclable remainder exists in the tailings and slag. Moreover, because the Ticontaining blast furnace slag is mostly dominated by a glass phase with very low chemical activity, coupled with a large variety of highly crystalline precipitated minerals present, the mineral phase is complicated, making it difficult to extract $\mathrm{TiO}_{2}$ by conventional physical or chemical methods. Therefore, the traditional blast furnace-converter process cannot achieve the enhanced migration and efficient separation of valuable components. According to the original ore, the utilization rate of vanadium and titanium is less than $50 \%$ and $20 \%$ respectively, and millions of tons of blast furnace slag containing about $20 \% \mathrm{TiO}_{2}$ are piled up unavailably, causing extremely serious waste of resources and environmental pollution, while seriously affecting economic benefits [5-6].

The non-blast furnace smelting of VTM abroad mainly uses the rotary kiln coal-based process. The advantages of the rotary kiln process are high efficiency, low production cost, and qualified products. However, the separation effect of iron, vanadium and titanium is extremely unsatisfactory, and it is difficult to achieve efficient and comprehensive utilization. In addition, various fire and wet process studies have also been conducted abroad [78].

The domestic VTM non-blast furnace comprehensive utilization process can be summarized as: the "North process" with vanadium extraction as the main feature and the "South process" with vanadium extraction as the main feature in the future. The northern process is: VTM concentrate is added with sodiumizing agent to mix the pellets oxidation and sodium roasting are carried out in the rotary kiln to convert V2O5 in the VTM concentrate into sodium metavanadate soluble in water. The sodium oxide pellets of the VTM concentrate are leached out of the aqueous solution through hot water Extract V2O5. The pellets immersed in vanadium are reduced, cooled and magnetically separated by a coal-based rotary kiln to obtain reduced pellets with an iron metallization rate of 90-92\%. The reducing pellets are melted by an electric furnace, and the final products are molten steel and liquid titanium slag.

The advantage of this process is that the yield of vanadium is high (90\%). The content of slag $\mathrm{TiO}_{2}$ obtained by electric furnace smelting is close to the theoretical calculation value, which is much higher than the $\mathrm{TiO}_{2}$ grade of blast furnace slag. Since there is no task of reducing vanadium during smelting and smelting, there is no excessive $\mathrm{Ti}$ in the molten iron, and $\mathrm{TiO}_{2}$ in the slag is not reduced or over-reduced, so there is no serious problem of "sticking to the can" of molten iron in the blast furnace process.However, the materials that need to be processed in this process are too expensive. To recover $0.40 \%$ of vanadium, all the concentrate must be processed. The amount of sodiumizing agent is large. Due to the influence of residual sodium salts after vanadium extraction, the pellets are reduced Easy to swell, Pulverization, resulting in poor stability of the reduction operation of the rotary kiln after the vanadium extraction, plus the rotary kiln for reduction Equipment, singlemachine production capacity is difficult to meet the needs of large-scale processing resources, so failed to achieve industrial production.

Compared with the northern process, the domestic prefers the southern process of iron extraction and vanadium extraction, that is, the VTM concentrate is pelletized, using coal as the reducing agent, and the onestep rotary kiln (chain grate-rotary kiln) is used to reduce the product. Through cooling and magnetic separation, reducing pellets are obtained, and the reducing pellets are deeply reduced by adding carbon in the ore-heating furnace to reduce all the vanadium into the molten iron and the melting separation. The electric furnace products are vanadium-containing molten iron and titaniumcontaining slag, vanadium-containing molten iron Vanadium-containing slag and semi-steel are obtained by blowing oxygen. The products of the whole process are vanadium-containing slag, semi-steel and titaniumcontaining slag. Some of these processes have been industrially tested, but due to high overall energy 
consumption, small ore processing capacity, and large environmental load, The recovery rate of vanadiumtitanium has not reached the expected target and other reasons, and there has been no successful industrial application or long-term operation [9-16].

The purpose of this study is to directly reduce the VTM using the gas-based shaft furnace process to achieve the comprehensive utilization of iron, titanium and vanadium in the VTM. In the process of gas-based direct reduction, it is not only possible to add limestone as a solvent. The grade of titanium slag is improved, and the titanium slag will not form perovskite, and the product obtained is relatively pure, which is beneficial to the separation of iron, titanium and vanadium. It is conservatively estimated that the demand for direct reduced iron in China is at least 10 million. The gap between the demand for direct reduced iron in China and the global output is very large, so the application prospect of direct reduced iron is very broad, and the demand is huge. From this perspective, China should also vigorously develop direct reduction iron technology, especially gas-based reduction technology.

The research content of this topic revolves around the VTM gas-based direct reduction process. The specific contents are as follows:

(1) XRF phase analysis of VTM.

(2) The thermodynamic calculation of the VTM gasbased direct reduction was carried out by FactSage thermodynamic calculation software. During the calculation, the mixed gas of $\mathrm{H}_{2}, \mathrm{CO}$ and $\mathrm{N}_{2}$ was used as the reducing gas. The effect of $\mathrm{CO}_{2} / \mathrm{CO}$ are designed to analyze the effect of different conditions on the direct reduction of VTM gas in conjunction with subsequent experimental studies.

\section{Materials and methods}

VTM concentrate used in this study originated from panxi region. The chemical composition of the sample is shown in table 1 . The main mineral phases of the raw material are magnetite $\mathrm{Fe}_{2} \mathrm{O}_{3}, \mathrm{Al}_{2} \mathrm{O}_{3}, \mathrm{SiO}_{2}$ and $\mathrm{Cr}_{2} \mathrm{O}_{3}$.

Table 1 The main component of the original ore.

\begin{tabular}{lcccc}
\hline $\begin{array}{l}\text { Raw } \\
\text { materials }\end{array}$ & $\mathrm{Fe}_{2} \mathrm{O}_{3}$ & $\mathrm{Al}_{2} \mathrm{O}_{3}$ & $\mathrm{SiO}_{2}$ & $\mathrm{Cr}_{2} \mathrm{O}_{3}$ \\
\hline $\begin{array}{l}\text { Mass } \\
\text { fraction(\%) }\end{array}$ & 87.12 & 4.33 & 2.12 & 1.23 \\
\hline
\end{tabular}

In this paper, thermodynamic calculation software is used to perform thermodynamic calculation on the gasbased direct reduction of VTM oxide pellets. Here it is necessary to focus on the method of thermodynamic calculation. The principles on which thermodynamic calculation is based are the law of conservation of mass, the law of conservation of energy, and the minimum of Gibbs free energy.

The VTM oxidized pellet gas group is directly reduced to a multi-component multi-phase system, and the total Gibbs free energy function is:

$$
G=G^{\alpha}+G^{\beta}+G^{\gamma}
$$

$\mathrm{G}$ is the total Gibbs free energy of the system, $\alpha, \beta$ and $\gamma$ are the gas phase, solid phase and liquid phase, and each phase can be replaced as follows:

$$
G^{\alpha}=\sum_{k} \mu_{k}^{\alpha} n_{k}^{\alpha} \quad G^{\beta}=\sum_{k} \mu_{k}^{\beta} n_{k}^{\beta} \quad G^{\gamma}=\sum_{k} \mu_{k}^{\gamma} n_{k}^{\gamma}
$$

Where represents different substances, substituting the three formulas can get the following substitutions:

$$
G=\sum_{\alpha} \sum_{k} n_{k}^{\alpha} \mu_{k}^{\alpha}
$$

Based on this function, the Lagrangian multiplier method can be used to calculate the equilibrium yield of each substance after the reaction. The Lagrangian function is as follows:

$$
L=G-\lambda \Psi=G-\sum_{j=1}^{l} \lambda_{j}\left(\sum_{k=1}^{N} a_{k j} n_{k}-b_{j}\right)
$$

To make the Lagrangian function get the extreme value, its partial differential needs to be 0 , as follows:

$$
\left(\frac{\partial L}{\partial n_{k}}\right)_{n_{i \neq k}}=0
$$

Finally, the system of equations can be obtained, through which the equilibrium output of each substance can be obtained.

The equilibrium calculation of gibbs function is based on Gibbs-Helmholtz equation and Van't-Hoff equation:

$$
\begin{aligned}
\mathrm{d}\left(\frac{\Delta G_{T}^{\theta}}{T}\right) & =-\frac{\Delta H_{T}^{\theta}}{T^{2}} \mathrm{~d} T \\
\frac{\mathrm{d} \ln K_{p}}{\mathrm{~d} T} & =\frac{\Delta H_{T}^{\theta}}{R T^{2}} \mathrm{~d} T
\end{aligned}
$$

The relation between the above two equations can be expressed by the following equation:

$$
\Delta G_{T}^{\theta}=-R T \ln K_{p}
$$

This equation exists to facilitate the equilibrium constant of the reaction. And in order to apply equation 1 , the relation between thermal effect $\Delta \mathrm{H}_{\mathrm{T}}^{\theta}$ and temperature of standard reaction is first obtained

$$
\mathrm{d} \Delta H_{T}^{\theta}=\Delta C_{p} \mathrm{~d} T
$$

In the formula, the difference between the sum of the molar constant pressure heat capacities of products and the sum of the molar constant pressure heat capacities of reactants is the reaction heat tolerance $\Delta \mathrm{C}_{\mathrm{p}}$

$$
\Delta C_{p}=\sum\left(n_{i} C_{p, i}\right)_{\text {products }}-\sum\left(n_{i} C_{p, i}\right)_{\text {reactants }}
$$

$\mathrm{n}_{\mathrm{i}}$ is the quantity (coefficient) of substance $\mathrm{I}$ in each substance participating in the reaction. The change rule of the heat capacity $C_{p}$ at the molar constant pressure with the temperature can be approximated by the following equation: 


$$
C_{p}=A_{1}+A_{2} \times 10^{-3} T+A_{3} \times 10^{5} T^{-2}+A_{4} \times 10^{-6} T^{2}+A_{5} \times 10^{8} T^{-3}
$$

So by equation 5 we can write $\Delta \mathrm{C}_{\mathrm{p}}$ as

$$
\Delta C_{p}=\Delta A_{1}+\Delta A_{2} \times 10^{-3} T+\Delta A_{3} \times 10^{5} T^{-2}+\Delta A_{4} \times 10^{-6} T^{2}+\Delta A_{5} \times 10^{8} T^{-3}
$$

And by equation 4, integral, we have

$$
\Delta H_{T}^{\theta}=\Delta A_{1} T+\frac{1}{2} \Delta A_{2} \times 10^{-3} T^{2}-\Delta A_{3} \times 10^{5} T^{-1}+\frac{1}{3} \Delta A_{4} \times 10^{-6} T^{3}-\frac{1}{2} \Delta A_{5} \times 10^{8} T^{-2}+A_{6}
$$

Similarly, thermal effect of standard reaction at normal temperature

$$
\Delta H_{298}^{\theta}=\sum\left(n_{i} \Delta H_{i, f, 298}^{\theta}\right)_{\text {products }}-\sum\left(n_{i} \Delta H_{i, f, 298}^{\theta}\right)_{\text {reactants }}
$$

Substitute $\Delta \mathrm{H}_{298}^{\theta}$ calculated from equation 9 and $\mathrm{T}=298 \mathrm{~K}$ into equation 8 , and with equation 1 we get

$$
\Delta G_{T}^{\theta}=-\Delta A_{1} T \ln T-\frac{1}{2} \Delta A_{2} \times 10^{-3} T^{2}-\frac{1}{2} \Delta A_{3} \times 10^{5} T^{-1}-\frac{1}{6} \Delta A_{4} \times 10^{-6} T^{3}-\frac{1}{6} \Delta A_{5} \times 10^{8} T^{-2}+A_{6}^{\prime} T+A_{6}
$$

$\mathrm{A}^{\prime}{ }_{6}$ in the above equation is the integral constant of Gibbs-Helmholtz equation. If the thermal effect of standard reaction $\Delta \mathrm{H}_{298}^{\theta}$ and the entropy difference of standard reaction $\Delta \mathrm{S}_{298}^{\theta}$ are known at normal temperature, then

$$
\begin{aligned}
\Delta G_{298}^{\theta} & =\Delta H_{298}^{\theta}-298 \Delta S_{298}^{\theta} \\
A_{6}^{\prime} & =\frac{\Delta G_{298}^{\theta}}{T}+\Delta A_{1} \ln T+\frac{1}{2} \Delta A_{2} \times 10^{-3} T+\frac{1}{2} \Delta A_{3} \times 10^{5} T^{-2}+\frac{1}{6} \Delta A_{4} \times 10^{-6} T^{2}+\frac{1}{6} \Delta A_{5} \times 10^{8} T^{-3}-A_{6} T^{-1}
\end{aligned}
$$

Equation 10 is the final formula for the Gibbs free energy of standard reaction by applying the standard reaction heat effect.

The theoretical molar quantity of ' $\mathrm{O}$ ' in $\mathrm{Fe}_{2} \mathrm{O}_{3}$ is 1.686 kmol. Theoretical Fe production is $1.124 \mathrm{kmol}$. The degree of addition ratio is defined based on the amount of oxygen in the substance, with an overdose ratio of 1.0 when $\mathrm{CO}$ reacts exactly with $\mathrm{Fe}_{2} \mathrm{O}_{3}$. And $\mathrm{CO}_{2}$ ratio is defined as the proportion of volume.

$$
\begin{gathered}
\psi_{\text {additional }}=\frac{n_{0}(\mathrm{CO})}{3 \times n_{0}\left(\mathrm{Fe}_{2} \mathrm{O}_{3}\right)} \\
\psi_{\mathrm{CO}_{2}}=\frac{V_{\mathrm{CO}_{2}}}{V_{\mathrm{CO}}+V_{\mathrm{CO}_{2}}}
\end{gathered}
$$

The thermodynamic analysis is conducted taking the following assumed conditions into account:

1. The mass of VTM concentrate is $100 \mathrm{~kg}$, and the atmosphere pressure is $0.1 \mathrm{MPa}$.

2. Phases with contents lower than $0.5 \%$ are not discussed in this paper.

3. The reaction component of reducer is regarded as pure $\mathrm{CO}$, the only impurity component is $\mathrm{CO}_{2}$, and the reaction is in the atmosphere of $25 \% \mathrm{~N}_{2}$.

\section{Results and discussion}

\subsection{Reactions of VTM concentrate reduction system}

The reaction can be spontaneous with the change of Gibbs free energy below zero, according to the gibbs principle of gibbs total free energy minimization. It shows by analyzing Gibbs free energy curve of the reaction with temperature in FIG 3 that: In the general smelting temperature range, $\mathrm{Al}_{2} \mathrm{O}_{3}, \mathrm{SiO}_{2}, \mathrm{Cr}_{2} \mathrm{O}_{3}$ will not be become reactants. With the temperature rising, $\mathrm{C}$ tends towards gas phase, and $\mathrm{Fe}_{2} \mathrm{O}_{3}$ spontaneously transforms to $\mathrm{FeO}$ from $843 \mathrm{~K}$.

$$
\begin{aligned}
& 2 \mathrm{CO}(g)=\mathrm{C}+\mathrm{CO}_{2}(g) \\
& \mathrm{FeO}+\mathrm{CO}(g)=\mathrm{Fe}+\mathrm{CO}_{2}(g) \\
& 2 \mathrm{FeO}+\mathrm{C}=2 \mathrm{Fe}+\mathrm{CO}_{2}(g) \\
& \mathrm{Fe}_{2} \mathrm{O}_{3}+3 \mathrm{CO}(\mathrm{g})=2 \mathrm{Fe}+3 \mathrm{CO}_{2}(g) \\
& \mathrm{Fe}_{2} \mathrm{O}_{3}+\mathrm{CO}(\mathrm{g})=2 \mathrm{FeO}+\mathrm{CO}_{2}(g) \\
& 3 \mathrm{Fe}_{2} \mathrm{O}_{3}+\mathrm{CO}(\mathrm{g})=2 \mathrm{Fe}_{3} \mathrm{O}_{4}+\mathrm{CO}_{2}(g) \\
& \mathrm{Fe}_{3} \mathrm{O}_{4}+4 \mathrm{CO}(\mathrm{g})=3 \mathrm{Fe}+4 \mathrm{CO}_{2}(g) \\
& \mathrm{Fe}_{3} \mathrm{O}_{4}+4 \mathrm{C}=3 \mathrm{Fe}+4 \mathrm{CO}(g) \\
& \mathrm{Fe}_{3} \mathrm{O}_{4}+2 \mathrm{C}=3 \mathrm{Fe}+2 \mathrm{CO}_{2}(g)
\end{aligned}
$$

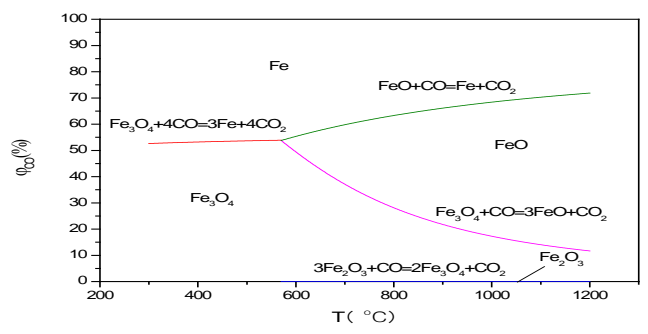

FIG.3 Gibbs free energy change curves of reactions with change of temperature.

\subsection{Effects of temperature on products}

With the temperature increasing, the reduction reaction is promoted, and the molar amount of iron increases gradually. The equilibrium composition of $\mathrm{Al}_{2} \mathrm{O}_{3}$ and $\mathrm{SiO}_{2}$ 
remains stable. Under the condition that reducing agent $\mathrm{CO}$ is sufficient (excess ratio of 22.5) and pure, $\mathrm{Fe}_{2} \mathrm{O}_{3}$ and $\mathrm{Fe}_{3} \mathrm{O}_{4}$ only exist stably below $900 \mathrm{~K}$, reducing to $1 \%$ of $\mathrm{Fe}$ element at $913 \pm 20 \mathrm{~K}$ and $853 \pm 20 \mathrm{~K}$ respectively. From $473 \mathrm{~K}$ to $1473 \mathrm{~K}$, the equilibrium composition of $\mathrm{FeO}$ increases firstly and then decreases. When the temperature reached $793 \pm 20 \mathrm{~K}$, the equilibrium component of $\mathrm{FeO}$ reached the peak value of $0.957 \mathrm{kmol}$. This is because when the temperature rises to $780 \mathrm{~K}$, according to the Gibbs free energy minimum principle, the CO

\section{(a)}

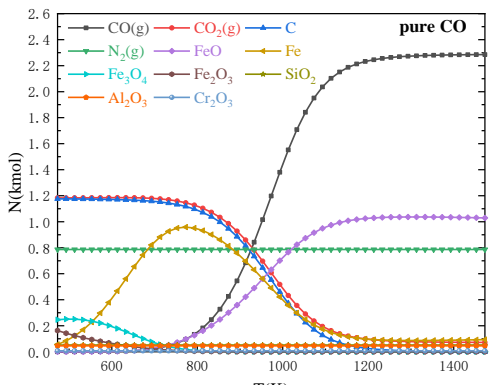

(c)

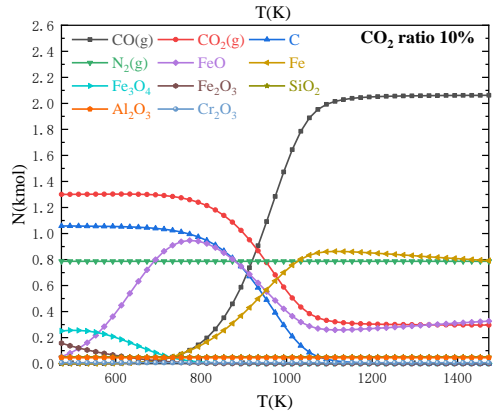

(e)

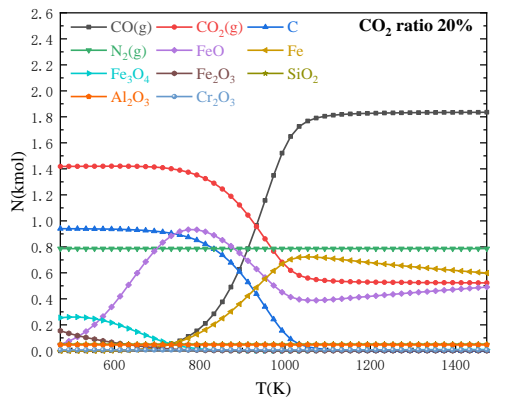

spontaneously disproportionates to form of $\mathrm{C}$ and $\mathrm{CO}_{2}$ (in fact, this reaction is only obvious under catalyst conditions). In a system without reductant atmosphere, C cannot reduce the oxide of $\mathrm{Fe}$ below $1000 \mathrm{~K}$, so $\mathrm{Fe}$ elements tend to be in the $\mathrm{FeO}$ form. And when the temperature is higher than $800 \mathrm{~K}, \mathrm{C}$ gasifies with $\mathrm{CO}_{2}$. For this reason, the equilibrium component of $\mathrm{FeO}$ is converted to $\mathrm{Fe}$ at high temperatures. The total production of Fe is $0.99795 \mathrm{kmol}$ at $1473 \mathrm{~K}$. As shown in FIG 4.

(b)

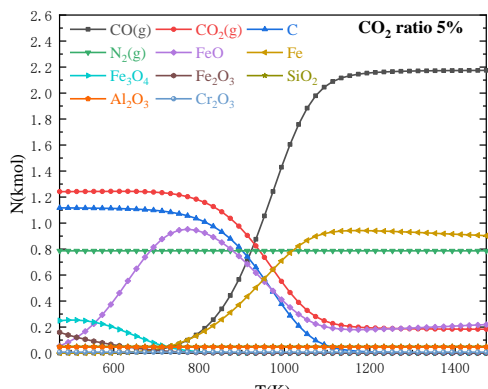

(d)

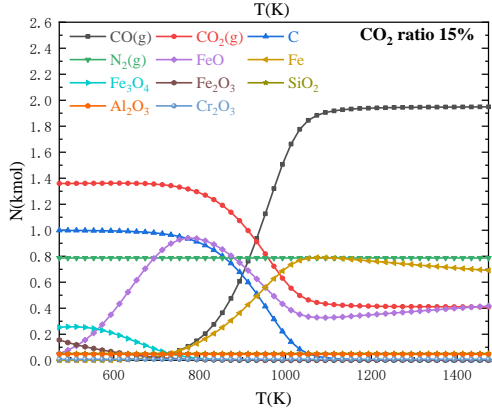

(f)

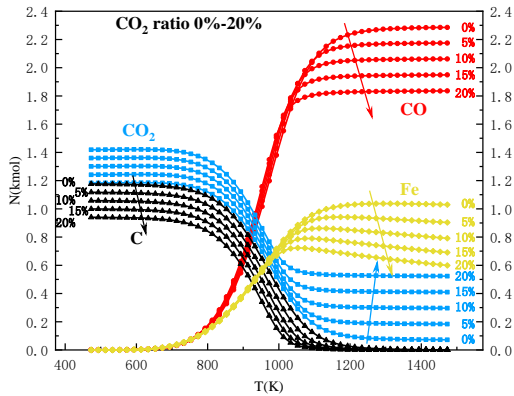

FIG.4 Effects of $\mathrm{CO}_{2}$ ratio and $\mathrm{T}$ in the $\mathrm{CO}-\mathrm{CO}_{2}$ system.

\subsection{Effects of temperature on reduction degree}

In order to facilitate the study of the relationship between reduction degree and temperature, the reduction degree is defined as follows:

$$
\eta=\frac{3 \times n_{0}\left(\mathrm{Fe}_{2} \mathrm{O}_{3}\right)-n_{1}(\mathrm{FeO})-3 \times n_{1}\left(\mathrm{Fe}_{2} \mathrm{O}_{3}\right)-4 \times n_{1}\left(\mathrm{Fe}_{3} \mathrm{O}_{4}\right)}{3 \times n_{0}\left(\mathrm{Fe}_{2} \mathrm{O}_{3}\right)}
$$

where $\mathrm{n} 0\left(\mathrm{Fe}_{2} \mathrm{O}_{3}\right)$ and $\mathrm{n} 0\left(\mathrm{Fe}_{3} \mathrm{O}_{4}\right)$ are the molar quantities of raw materials $\mathrm{Fe}_{2} \mathrm{O}_{3}$ and $\mathrm{Fe}_{3} \mathrm{O}_{4}$ before reduction, and $\mathrm{n} 1(\mathrm{FeO}), \quad \mathrm{n} 1\left(\mathrm{Fe}_{2} \mathrm{O}_{3}\right)$ and $\mathrm{n} 1\left(\mathrm{Fe}_{3} \mathrm{O}_{4}\right)$ are the molar quantities of $\mathrm{FeO}, \mathrm{Fe}_{2} \mathrm{O}_{3}$ and $\mathrm{Fe}_{3} \mathrm{O}_{4}$ in the equilibrium phase after reduction, respectively.

FIG.5 shows that the degree of reduction first increased with the increase of temperature, and reached 95\% of the maximum value at $1100 \pm 50 \mathrm{~K}$, and then began to fall. The equilibrium constant is obtained by the following formula. When the temperature is high, reaction 2 is inhibited, and the reverse reaction is promoted, so that a small amount of $\mathrm{Fe}$ is converted to $\mathrm{FeO}$. 
(a)

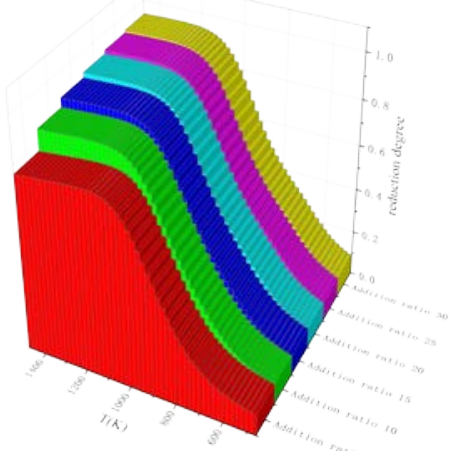

(b)

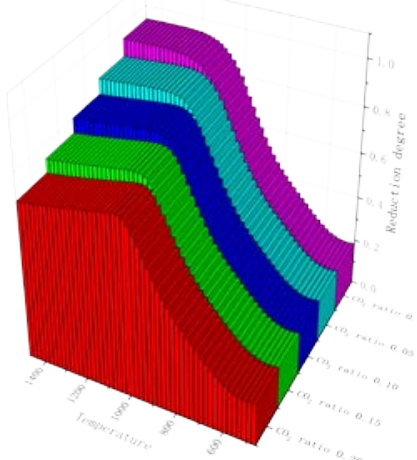

FIG.5 (a) Effects of addition ratio on reduction degree(pure CO) (b) Effect of $\mathrm{CO}_{2}$ ratio on reduction degree(addition ratio 30).

\subsection{Effects of addition ratio of reducer}

When the reduction reaction of iron oxide is calculated, different proportion of reducing agent is considered. According to the current thermodynamic analysis, the value range of $\mathrm{CO} / \mathrm{O}$ entering $\mathrm{CO}$ in $\mathrm{Fe}_{2} \mathrm{O}_{3}$ in this paper is 5-30. The influence of this condition on equilibrium components is shown in FIG.6 (a) - (h). The addition of reducing agent will change the proportion of equilibrium components.

As shown in FIG.6, with the increase of the addition amount of reducing agent, the composition of $\mathrm{C}, \mathrm{CO}$ and $\mathrm{CO}_{2}$ increases in the same proportion, and at the same temperature, the amount of the substance varies very evenly with $\mathrm{CO} / \mathrm{O}$.

As shown in FIG.6 (h), with the increase of CO/O, the composition of $\mathrm{Fe}$ and $\mathrm{FeO}$ increases and the composition

(a)

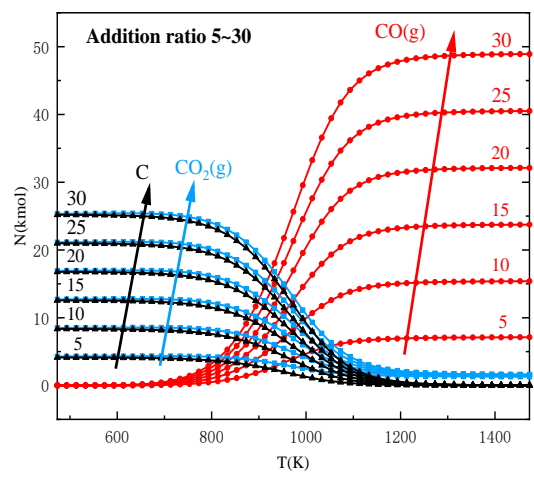

of $\mathrm{Fe}_{3} \mathrm{O}_{4}$ decreases at the same temperature. Moreover, the change of the amount of $\mathrm{Fe}$ and $\mathrm{FeO}$ gradually slows down with the increase of $\mathrm{CO} / \mathrm{O}$ at the same temperature. This is easily explained by the equilibrium constant $\mathrm{Kp}$.

As shown in FIG.6, the curve trend of reduction degree with the proportion of adding reducing agent: when the temperature reaches $1100 \pm 50 \mathrm{~K}$, the reduction degree reaches the maximum. With the increase of $\mathrm{CO} / \mathrm{O}$, the maximum reduction degree gradually approaches 1.0000 and the increment gradually decreases, while the maximum peak moves towards high temperature. explanation

When the addition ratio of reducing agent is greater than 15 , the reduction degree tends to be stable with the change of temperature after the maximum peak. This is because the large amount of $\mathrm{CO}$ atmosphere inhibits the occurrence of reaction 2 .

(b)

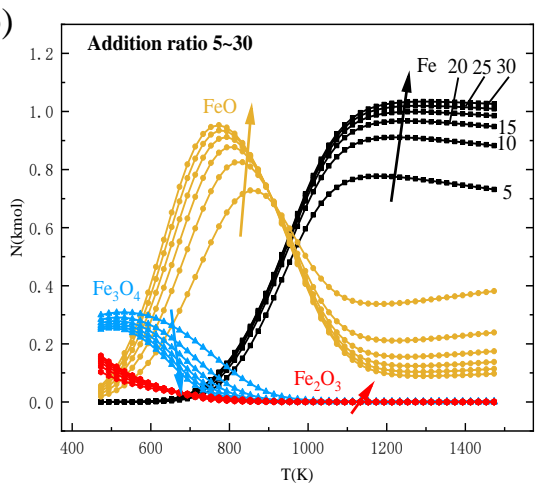

FIG.6 Effects of excess reducer addition ratio and T on equilibrium composition.

\section{Conclusion}

Based on Literature review and Thermogravimetric analysis of direct reduction of VTM based on phase equilibrium calculation model are carried out. The conclusions are as follows.

(1) The contents in VTM reduction system are simplified as 4 kinds of chemical compositions.

(2) The effects of temperature and addition ratio on the equilibrium system are fully studied.

\section{References}

1. Chen D. S, Sung B, Wing L, N et al. $\square$ state reducing Panzhhihua titanomagnet.cncentrates. what.pullverized.coal.[J].MineralsEnergying, 2011, 24 (4): 864-869.

2. Hu T, Lv XW, Bai C, G et al. Reducing Behavior of Panzhhihua titanomagnet. cncentrates. what. coal.[J].Metaling and Materials Transactions. B, 2013, 44 (4): 252-260.

3. Zhanging L, Zhanging L, N, Wng M, Y, et al. Recovery Titanium Communications from Ti- 
bearing bladder slag under they dynamic ox xi ia dio ning $[\mathrm{J}]$. Minerals, Engingering, 2007, 20 (2): 684-693.

4. Chen S. Y, Chu M. S.and vanadium titanomagnetite [J].International Journal of Minerals, Metallurgy and Materials, 2014, 21 (3): 225-232.

5. Ozturk B, Fruehan R. slag [J]. Metalogy and Materials Transactions B, 2013, 26 (4): 1086-1088.

6. Liu, Y, H, Lv, X, W, Bai, C, G. Density of blast furnace bering $\mathrm{TiO}_{2}$ at 1673. K. [J], ISIJ. Internatonal, 2014, 54 (9): 2017-2020.

7. Jena. B. C, Dresler. W, Reilly. I. G. Extraction of titanium, vanadium and and iron from titanomagnetite Minerals, Engeringer, 1995, 8 (1): 159-168.

8. Biswas R, K, Islam, M, F, Hab, M, A. Professional Ilmenite through salt-water. vapor. roasting. and learning. [J]. Hydrometalugry, 1996, 42 (2): 367375.

9. Klawonn R M, Siuka D. Current status and future of the Midrex direct reduction technology. 2006,126(3): 23-29.

10. Shams A, Moazeni F. Modeling and Simulation of the MIDREX Shaft Furnace: Reduction, Transition and Cooling Zones. JOM, 2015,67(11): 2681-2689.

11. Huitu K, Helle M, Helle H, Marko K K, Henrik S. Optimization of Midrex Direct Reduced Iron Use in Ore-Based Steelmaking. 2015,86(5): 456-465.

12. Kopfle J, Hunter R. Direct reduction's role in the world steel industry. 2008,35(4): 254-259.

13. Hu J G. Development of Gas-Based Shaft Furnace Direct Reduction Technology. 2009,16: 1288-1291.

14. Rob C. Gasification and the Midrex Dirext Reduction Process: Gasification Technologies Conference, 1999[C].

15. Maschlanka W, Post G. Midrex Process For Direct Reduction of IRON-ORE. Revue De MetallurgieCahiers D Informations Techniques, 1975,72(11): 781-794.

16. Chaudhary N. Midrex Direct Reduction Plant. Brichaut, F. 2000: 339-341. 